\title{
Comprehensive Analysis and Design of LLC Resonant Converter With Magnetic Control
}

\author{
Yuqi Wei, Quanming Luo, and Alan Mantooth
}

\begin{abstract}
Conventionally, LLC resonant converter adopts frequency control (FC) or combine FC with phase shift control (PSC) to regulate the output voltage. However, for both control strategies, a variable switching frequency operation range is required, which makes the magnetic component and driver circuit design complicated. In this paper, the magnetic control (MC) or variable inductor control is adopted for the LLC resonant converter. Thanks to $\mathrm{MC}$, constant switching frequency and duty cycle can be implemented for the primary switches. A comprehensive analysis of the magnetically controlled LLC resonant converter is presented, which includes the operation principle, voltage gain, and soft switching operation. Meanwhile, a design methodology for LLC resonant converter with MC is proposed, especially the design considerations for the variable inductor are discussed. By adopting the proposed design methodology, the zero voltage switching (ZVS) operation for the primary switches and the zero current switching (ZCS) operation for the secondary rectifier can be achieved. Finally, a $200 \mathrm{~W}$ experimental setup is built to validate the theoretical analysis.
\end{abstract}

Index Terms-Design methodology, LLC resonant converter, magnetic control, soft switching.

\section{INTRODUCTION}

$\mathrm{L}$ LC resonant converters have drawn much attention and been widely used due to their characteristics of wide range operation, soft switching capability, and high power density [1]-[19].

From the control strategy point of view, frequency control (FC) is the most frequently used control strategy for the LLC resonant converter [8], [9]. By adjusting the switching frequency, the input impedance of the resonant network can be modified, and finally the converter output voltage can be regulated. However, a wide switching frequency operation range is required to satisfy the system input voltage and output

Manuscript received June 16, 2019; revised Augest 6, 2019 and October 17, 2019; accepted November 21, 2019. Date of publication December 30, 2019; date of current version November 28, 2019. This work was supported by the China National Science Foundation under Grant 51577019. This paper was presented in part at the 2019 IEEE 10th International Symposium on Power Electronics for Distributed Generation Systems (PEDG), Xi'an, China, June 2019.

Y. Wei and Q. Luo are with the State Key Laboratory of Power Transmission Equipment and System Security and New Technology, Chongqing University, Chongqing, China (e-mail: yuqiwei@uark.edu; lqm394@126.com).

A. Mantooth is with the Department of Electrical Engineering, University of Arkansas, Fayetteville, USA (e-mail: mantooth@uark.edu).

Digital Object Identifier 10.24295/CPSSTPEA.2019.00025 power requirement.The following problems will be caused for wide switching frequency operating range: 1) poor electronicmagnetic-interference (EMI) performance; 2) complicated design of magnetic component and driver circuit; 3) low power density; and 4) high conduction losses. To narrow the variable switching frequency range, control strategies based on combining FC and phase shift control (PSC) have been proposed in [10], [11]. In addition, different combination strategies are analyzed and proposed to improve the system efficiency [12], [13]. Nonetheless, these control strategies still suffer from variable switching frequency range, high turnoff currents for the primary switches, and complicated control algorithms.

In order to further narrow the switching frequency operation range, some topologies based on the modifications of LLC resonant converter structure are proposed [15], [16]. In [15], a topology, which integrates half-bridge LLC resonant converter and full-bridge LLC resonant converter, is proposed. The proposed topology adopts pulse width modulation (PWM) to achieve the fixed switching frequency operation of the LLC resonant converter. In [16], a modified LLC resonant converter with two transformers in series is proposed, and the proposed topology has four operation configurations. The required switching frequency operation range is reduced by adjusting the converter's operation mode. However, these topologies suffer from the following problems: 1) additional switches are required to re-configure the system structure, which leads to complexity of the system; 2) in addition, these additional switches are operating at hard-switching and will generate additional power losses; 3) for the proposed topology in [16], although the switching frequency operation range is reduced, a variable switching frequency range is still necessary to regulate the output of the converter. In [17], a dual full-bridge LLC resonant converter topology is proposed. An additional switch and resonant capacitor are required to adjust the operation modes of the LLC resonant converter, namely, constant output current mode and constant output voltage mode. Although the constant output voltage mode is verified and has been widely used, the constant output current mode especially its accuracy still needs to be proved. In [18], the experimental results demonstrate that the accuracy of the constant output current mode is unsatisfactory, so a variable switching frequency range is still required. Overall, all of these topologies still need to adopt either FC, PSC or PWM to implement the closedloop control. Although the switching frequency range can be 
TABLE I

Comparison Among Different Analysis Methodologies

\begin{tabular}{|c|c|c|c|c|}
\hline $\begin{array}{l}\text { Control } \\
\text { strategy }\end{array}$ & $\begin{array}{l}\text { Switching } \\
\text { frequency } \\
\text { range }\end{array}$ & $\begin{array}{c}\text { Magnetic } \\
\text { component and } \\
\text { driver circuit } \\
\text { design }\end{array}$ & Complexity & $\begin{array}{c}\text { Extra } \\
\text { loss }\end{array}$ \\
\hline $\mathrm{FC}$ & Wide & Complicated & Simple & No \\
\hline $\mathrm{FC} \& \mathrm{PSC}$ & Narrow & Complicated & Complicated & No \\
\hline $\mathrm{MC}$ & Fixed & Simple & Simple & Yes \\
\hline
\end{tabular}

Note: Extra control winding is required.

reduced, the problems still present.

To solve the abovementioned problems, the magnetic control (MC), also called variable inductor control, has been proposed for LED drivers and resonant converter applications [18]-[27]. For MC, the output voltage is regulated by adjusting the variable inductor value. Therefore, a constant switching frequency and duty cycle can be implemented for the primary switches, so the magnetic component can be optimized.

The advantages and disadvantages of each control strategy have been summarized in Table I. For the MC, the fixed switching frequency operation can be achieved, while for the other two control strategies, a variable switching frequency operation range is required. It is known that the magnetic component and driver circuit design are related to the operating switching frequency. Therefore, the design of magnetic component and driver circuit are complicated for the FC and combined FC with PSC due to the variable switching frequency operation. Regarding the control circuit complexity, the $\mathrm{MC}$ requires a voltage controlled current source (VCCO) to transfer the control voltage signal obtained from PI controller to $\mathrm{DC}$ bias current. Then, the variable inductance value can be adjusted. Similarly, for the FC, it requires a voltage controlled oscillator (VCO) to transfer the control voltage signal obtained from PI controller to frequency signal, so that the operating switching frequency is adjusted. Based on this analysis, the complexity of the control circuit for $\mathrm{MC}$ and $\mathrm{FC}$ are viewed as simple compared with combined FC and PSC control strategy. It can be seen from Table I that the MC has many advantages compared with FC and PSC. The main disadvantage introduced by $\mathrm{MC}$ is the control windings' loss, which will be discussed in detail.

Many publications have focused on the analysis and design of the LLC resonant converter with FC or PSC. However, few publications focus on the LLC resonant converter with MC. In [24], [25], an LLC resonant converter with MC is proposed for the battery charger application. The traditional fundamental harmonic analysis (FHA) method has been used to analyze and design the magnetically controlled LLC resonant converter. However, they all lack a comprehensive analysis and design of the LLC resonant converter with MC. In addition, for the LLC resonant converter with MC, unlike FC, only the normalized switching frequency is adjusted. In this case, the normalized switching frequency, inductor ratio, and quality factor are all changed, which brings difficulty to analyze and design. Therefore, it is of great importance to give a comprehensive analysis on the magnetically controlled LLC resonant converter, and investigate the corresponding design

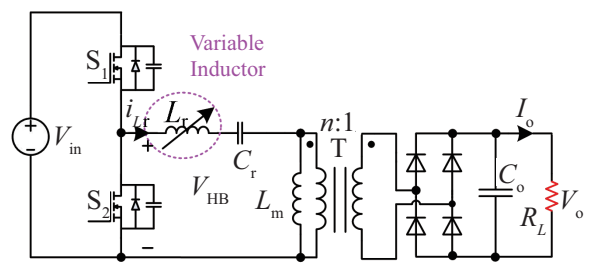

Fig. 1. Half-bridge LLC resonant converter with magnetic control.

methodology.

This paper is an extended version of the conference paper [27], and it is organized as follows: in Section II, a comprehensive analysis for the magnetically controlled LLC resonant converter is illustrated, which mainly includes operation principle, voltage gain, soft switching operation, and power loss analysis. Then, the proposed design methodology for the LLC resonant converter with magnetic control is presented in Section IV. Finally, experimental results from a $200 \mathrm{~W}$ prototype are shown to validate the theoretical analysis.

\section{Comprehensive Analysis of the Magnetically Controlled LlC Resonant Converter}

Unlike the traditional frequency control, by adjusting the switching frequency, only the normalized switching frequency is changed, and the relationship between the voltage gain and normalized switching frequency can be easily obtained. However, for the magnetic control, by adjusting the variable resonant inductor value, the normalized switching frequency, inductor ratio, and quality factor are all affected. Therefore, a comprehensive analysis of the LLC resonant converter with magnetic control is required. In this part, the operation principle, voltage gain, soft switching operation, and power loss analysis for the magnetically controlled LLC resonant converter are discussed.

\section{A. Operation Principle}

Fig. 1 shows the topology of the half-bridge LLC resonant converter with magnetic control. The variable resonant inductor value is adjusted to regulate the output voltage. The definitions of the inductor ratio $K$, the quality factor $Q$, the series resonant angular frequency $\omega_{\mathrm{r}}$, the parallel resonant angular frequency $\omega_{\mathrm{m}}$, and the normalized switching frequency $f_{\mathrm{n}}$ are defined as:

$$
\left\{\begin{array}{l}
K=\frac{L_{\mathrm{m}}}{L_{\mathrm{r}}} \\
\omega_{\mathrm{r}}=2 \pi f_{\mathrm{r}}=\frac{1}{\sqrt{L_{\mathrm{r}} C_{\mathrm{r}}}} \\
Q=\frac{\sqrt{L_{\mathrm{r}} / C_{\mathrm{r}}}}{R_{\mathrm{ac}}} \\
\omega_{\mathrm{m}}=2 \pi f_{\mathrm{m}}=\frac{1}{\sqrt{\left(L_{\mathrm{r}}+L_{\mathrm{m}}\right) C_{\mathrm{r}}}} \\
f_{\mathrm{n}}=\frac{f_{\mathrm{s}}}{f_{\mathrm{r}}}
\end{array}\right.
$$




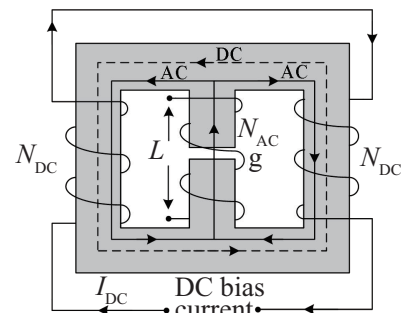

(a)

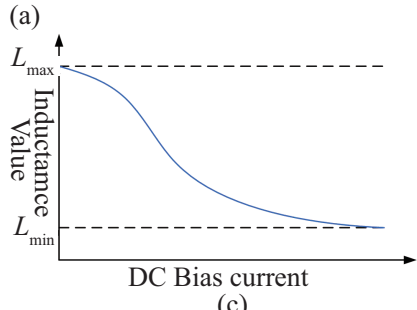

(c)

Fig. 2. Operation principle of the variable inductor. (a) Physical structure. (b) Principle of operation. (c) The relationship between DC bias current and inductance value.

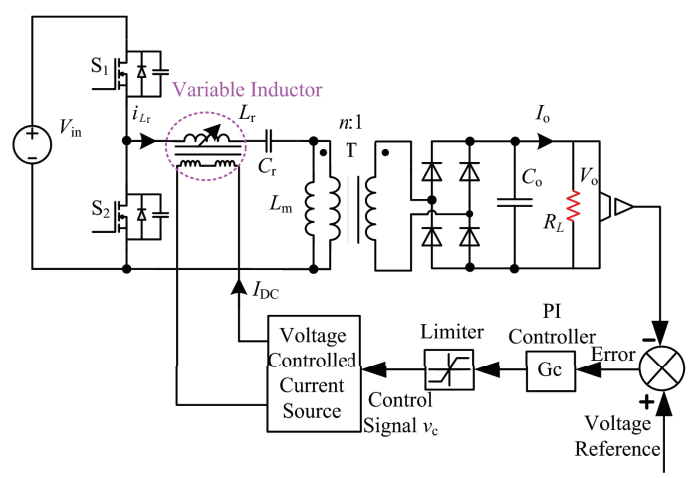

Fig. 3. Proposed control strategy for the LLC resonant converter with magnetic control.

where $R_{\mathrm{ac}}$ is the equivalent resistance of the rectifier network.

Fig. 2(a) shows the typical structure of a variable inductor with double E cores, where the control winding or auxiliary winding is placed on the outer arms without air gap, while the main inductance is wound on the central arm with air gap. The DC bias current $I_{\mathrm{DC}}$ is the current goes through the control winding of the variable inductor as shown in Fig. 2(a), which generates a DC bias magnetic flux density inside the magnetic material, thus adjusting the material magnetic permeability by changing the DC operating point around the knee of the $B-H$ curve as shown in Fig. 2(b). It can be seen that with the increase of the DC bias current, the material magnetic permeability is decreased, and finally decreases the variable inductance value. Therefore, typically, the variable inductance is inversely proportional with its DC bias control current as shown in Fig. 2(c).

Fig. 3 shows the proposed control strategy of the LLC resonant converter with magnetic control. The operation principle can be described as follows: when the output voltage is less than the reference voltage, after PI controller, the voltage control signal $v_{\mathrm{c}}$ will increase, so does the output current of the voltage controlled current source $I_{\mathrm{DC}}$. Then, based on the

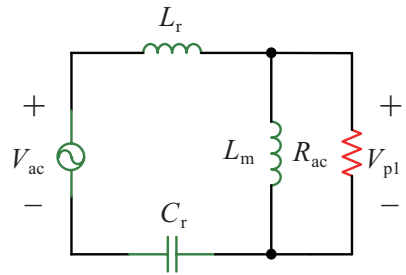

Fig. 4. FHA model of the LLC resonant converter.

relationship between the DC control current and the variable inductance value, the resonant inductance $L_{\mathrm{r}}$ will be decreased.

The normalized switching frequency, inductor ratio, and quality factor are all affected by the decrease of variable resonant inductor. Specifically, the inductor ratio is increased, which will decrease the voltage gain based on the analysis results of traditional LLC resonant converter with frequency control; but the quality factor is decreased, which will increase the voltage gain; for the normalized switching frequency, it is decreased, so the voltage gain should be increased. It would be difficult to reach the conclusion whether the voltage gain is increased or not by using the results obtained from the frequency control. Therefore, for the magnetically controlled LLC resonant converter, a clear conclusion can be drawn from the impedance point of view. Since the switching frequency is constant, the resonant inductor impedance and total input impedance is decreased, while other impedances remain unchanged. Therefore, according to the voltage divider law, the output voltage is increased and finally equals the reference voltage. However, the relationship between the variable resonant inductor value and the system voltage gain is still required, and the detailed analysis of the voltage gain is presented in next part.

\section{B. Voltage Gain}

Fig. 4 shows the converter model obtained by using the fundamental harmonic approximation (FHA) method, where $V_{\text {ac }}$ is the fundamental harmonic of the resonant network input voltage, and $V_{\mathrm{p} 1}$ is the fundamental harmonic of the transformer primary side voltage [18].

Based on Fig. 4, the output voltage of the LLC resonant converter can be derived according to the voltage divider law as below.

$$
\begin{gathered}
V_{\mathrm{p} 1}(s)=V_{\mathrm{ac}} \frac{\frac{L_{\mathrm{m}} s R_{\mathrm{ac}}}{L_{\mathrm{m}} s+R_{\mathrm{ac}}}}{L_{\mathrm{r}} s+\frac{1}{C_{\mathrm{r}} s}+\frac{L_{\mathrm{m}} s R_{\mathrm{ac}}}{L_{\mathrm{m}} s+R_{\mathrm{ac}}}} \\
=V_{\mathrm{ac}} \frac{L_{\mathrm{m}} C_{\mathrm{r}} R_{\mathrm{ac}} s^{2}}{L_{\mathrm{m}} L_{\mathrm{r}} C_{\mathrm{r}} s^{3}+\left(L_{\mathrm{r}}+L_{\mathrm{m}}\right) C_{\mathrm{r}} R_{\mathrm{ac}} s^{2}+L_{\mathrm{m}} s+R_{\mathrm{ac}}} \\
R_{\mathrm{ac}}=\frac{8 n^{2}}{\pi^{2}} R_{L} \\
V_{\mathrm{p} 1}=\frac{2 \sqrt{2} n}{\pi} V_{\mathrm{o}}
\end{gathered}
$$




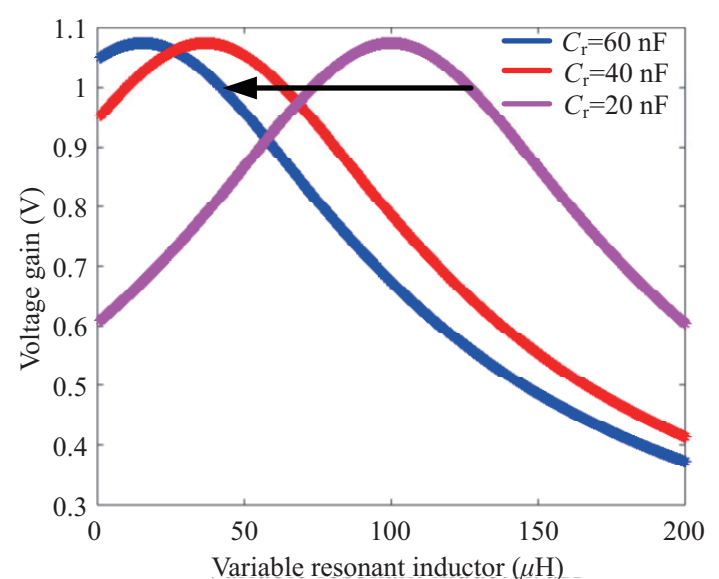

Fig. 5. Voltage gain curve with different resonant capacitor values.

$$
V_{\mathrm{ac}}=\frac{\sqrt{2}}{\pi} V_{\mathrm{in}}
$$

The voltage gain is defined as: $M=n V_{\mathrm{o}} /\left(V_{\text {in }} / 2\right)$. Then, by substituting (4) and (5) into (2), the following equation can be obtained.

$$
M=\left|\frac{1}{\frac{L_{\mathrm{r}} s}{R_{\mathrm{ac}}}+\frac{L_{\mathrm{r}}}{L_{\mathrm{m}}}+\frac{1}{C_{\mathrm{r}} R_{\mathrm{ac}} s}+\frac{1}{L_{\mathrm{m}} C_{\mathrm{r}} s}+1}\right|
$$

By substituting $s=2 \pi f_{\mathrm{s}} \mathrm{j}$ into equation (6) and rearranging it, the system voltage gain can be expressed as

$$
M=\frac{1}{\sqrt{\left[\frac{2 \pi f_{s}}{R_{\mathrm{ac}}} L_{\mathrm{r}}+\frac{-1}{C_{\mathrm{r}} R_{\mathrm{ac}}\left(2 \pi f_{s}\right)}\right]^{2}+\left[\frac{1}{L_{\mathrm{m}}} L_{\mathrm{r}}+\frac{L_{\mathrm{m}} C_{\mathrm{r}}\left(2 \pi f_{s}\right)^{2}-1}{L_{\mathrm{m}} C_{\mathrm{r}}\left(2 \pi f_{s}\right)^{2}}\right]^{2}}}
$$

For the magnetically controlled LLC resonant converter, the relationshipbetween the voltage gain and the variable resonant inductor $L_{\mathrm{r}}$ should be found, so equation (7) can be expressed as

$$
\begin{aligned}
M & =\frac{1}{\sqrt{\left(a L_{\mathrm{r}}+b\right)^{2}+\left(c L_{\mathrm{r}}+d\right)^{2}}} \\
& =\frac{1}{\sqrt{\left(a^{2}+c^{2}\right) L_{\mathrm{r}}^{2}+(2 a b+2 c d) L_{\mathrm{r}}+b^{2}+d^{2}}}
\end{aligned}
$$

Please note that the parameter $a, b, c$, and $d$ can be found according to (7). The relationship between the voltage gain, variable resonant inductor, magnetizing inductor, and resonant capacitor should be investigated. Based on (8), Fig. 5 shows the voltage gain curve with different resonant capacitor values when $f_{\mathrm{s}}=100 \mathrm{kHz}, L_{\mathrm{m}}=200 \mu \mathrm{H}, n=2$, and $R_{L}=10 \Omega$. It can be seen that with different resonant capacitor values, the peak voltage gain remains unchanged, and with the increase of the resonant capacitor values, the peak gain operation point is shifting from the right side to the left side.

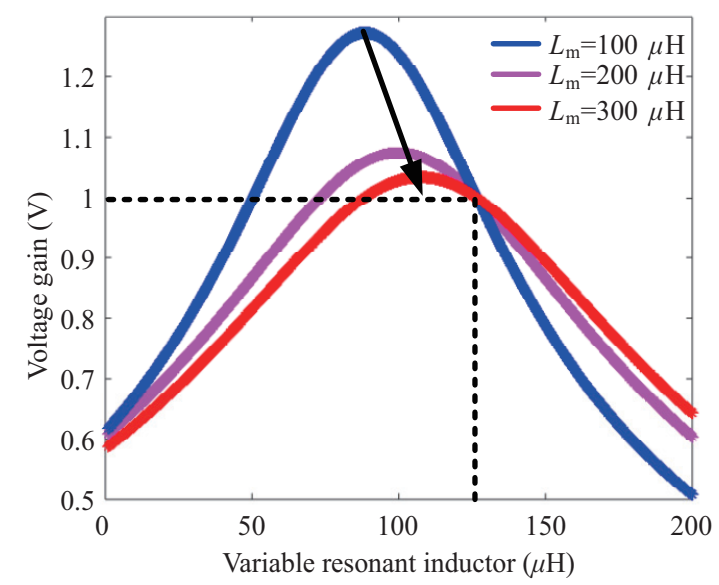

Fig. 6. Voltage gain curve with different magnetizing inductor values.

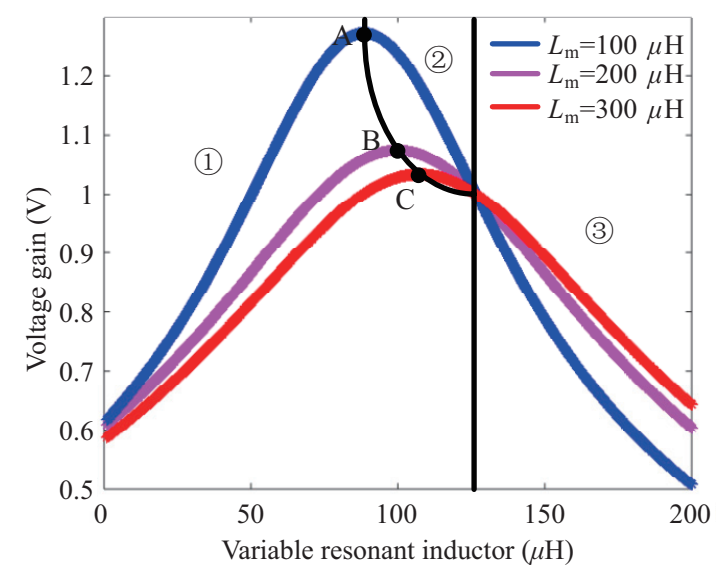

Fig. 7. Voltage gain curve with different magnetizing inductor values.

Fig. 6 shows the voltage gain curve with different magnetizing inductor values when $f_{\mathrm{s}}=100 \mathrm{kHz}, C_{\mathrm{r}}=20 \mathrm{nF}, n=2$, and $R_{L}=10 \Omega$. It can be seen that magnetizing inductor value has a great influence on the system voltage gain. Specifically, with the increase of the magnetizing inductor value, the peak voltage gain is decreased. Also, when the resonant capacitor value is determined, the unity gain operation point is fixed.

\section{Soft Switching}

To achieve high efficiency conversion, soft switching operation for the LLC resonant converter should be guaranteed. Therefore, it is necessary to analyze the soft switching operation of the LLC resonant converter with magnetic control. Based on the peak voltage gain and unity gain, the LLC resonant converter is divided into three regions as shown in Fig. 7. The peak voltage gain is the boundary between the capacitive region and the inductive region of the resonant network input impedance as shown in Fig. 8, when the input impedance angle is positive, it is operating in inductive region, otherwise, it is operating in capacitive region.

For region 1, it is located at the left side of both lines, it is operating in capacitive region, so the zero current switching 


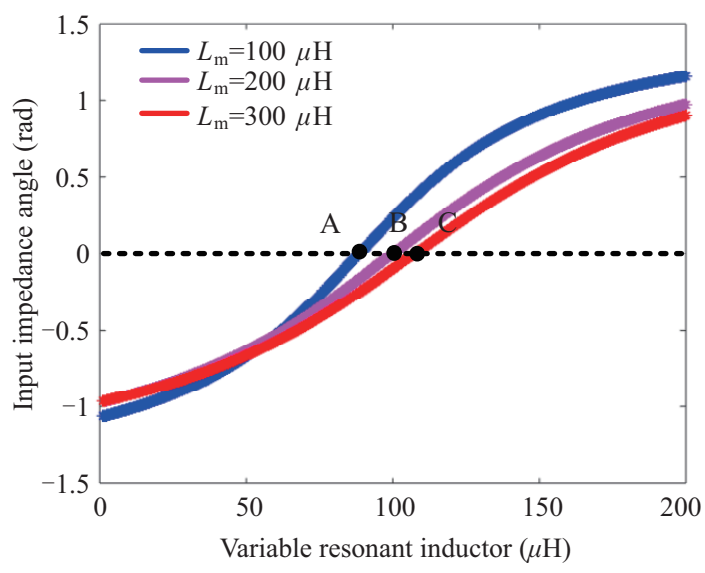

Fig. 8. The relationship between the input impedance angle and the variable resonant inductor with different magnetizing inductor values.

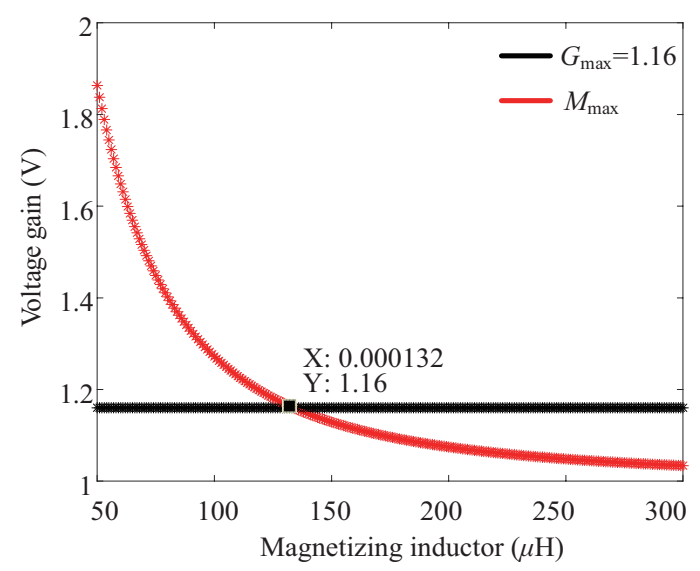

Fig. 9. Relationship between the maximum voltage gain and the magnetizing inductor value.

(ZCS) operation for the primary switches is achieved, since the switching frequency is lower than the series resonant frequency, the ZCS operation for the secondary rectifier is achieved. For region 2, it is located at the right side of the peak voltage gain curve and the left side of the unity gain curve, it is operating in inductive region, so the zero voltage switching (ZVS) operation for the primary switches is achieved, and the ZCS operation for the secondary rectifier is achieved. For region 3 , the converter is operating in inductive region, the ZVS operation for the primary switches is achieved, since the switching frequency is higher than the series resonant frequency, the ZCS operation for the secondary rectifier is lost. For the MOSFETs, the ZVS operation is preferred, so the desired operation region for the LLC resonant converter is region 2.

Next, the soft switching operation condition for the magnetically controlled LLC resonant converter is analyzed mathematically. For the ZVS operation of the primary switches, according Figs. 8 and 9, the ZVS operation is guaranteed when the variable resonant inductor $L_{\mathrm{r}}$ is at the right side of the peak voltage gain operation point, which can be expressed as

$$
L_{\mathrm{r}, \min } \geqslant \frac{-(a b+c d)}{a^{2}+c^{2}}
$$

To guarantee the ZCS operation of thesecondary rectifier, the switching frequency should be lower than the series resonant frequency during the whole operation range, so the following inequity should be satisfied.

$$
L_{\mathrm{r}, \mathrm{max}} \leqslant \frac{1}{4 \pi^{2} C_{\mathrm{r}} f_{s}^{2}}
$$

\section{Power Loss Analysis}

For the magnetically controlled LLC resonant converter, the power loss mainly include the following aspects: 1) variable resonant inductor loss; 2) primary switch loss; 3) output capacitor loss; 4) transformer loss; 5) secondary rectifier loss; 7) driver circuit loss; 8) control circuit loss. Compared with the traditional power loss analysis of the frequency controlled LLC resonant converter [28], the differences only exist in variable resonant inductor loss, transformer loss, and control circuit loss. Therefore, only the discussion of the variable resonant inductor loss, transformer loss, and control circuit loss are presented in this paper.

\section{1) Variable Resonant Inductor Loss}

For the variable resonant inductor loss $P_{L r}$, the following three parts are included: 1) core loss $P_{\text {core } L r} ; 2$ ) winding loss $\left.P_{\text {winding } L r} ; 3\right)$ and control winding loss $P_{\text {control } L r}$.

For the core loss, according to [20], the peak value of the flux density can be expressed as

$$
B=\frac{N_{\mathrm{AC}} A_{L \_L \mathrm{r}}}{A_{\mathrm{e} \_L \mathrm{r}}} I_{\mathrm{pk}}
$$

where $A_{L_{L} \mathrm{r}}$ is the inductance factor, $A_{\mathrm{e} L \mathrm{r}}$ is the effective area of the core, and $I_{\mathrm{pk}}$ is the peak value of the AC current.

Then, according to [20], the magnetic core loss of the variable inductor can be approximated by using the peak flux density and the losses characteristics given by the manufacturer.

For the winding loss, the Dowell model, which describes the ratio between the dc resistance $R_{\mathrm{dc}}$ and the ac resistance $R_{\mathrm{ac}}$, is used to calculate the equivalent ac resistance $R_{\mathrm{ac}}$. The dc resistance $R_{\mathrm{dc}}$ can be expressed as

$$
R_{\mathrm{dc}}=\frac{\rho L_{\mathrm{avg}} N}{S}
$$

where $\rho$ is the resistivity, $L_{\text {avg }}$ is the average length of one turn, $N$ is the total turns, and $S$ is the cross section area of the copper winding.

The ac resistance $R_{\mathrm{ac}}$ can be derived as

$$
R_{\mathrm{ac}}=k R_{\mathrm{dc}}
$$


where $k$ is the coefficient that can be determined by the Dowell model.

Finally, the winding loss can be calculated as

$$
P_{\text {winding }}=I_{\mathrm{ac}}^{2} \times R_{\mathrm{ac}}+I_{\mathrm{dc}}^{2} \times R_{\mathrm{dc}}
$$

For the control winding loss, based on (13), the equivalent dc resistance $R_{\mathrm{dc} \text { control }}$ can be calculated. Then, the control winding loss can be expressed as

$$
P_{\text {control_LB }}=I_{\mathrm{DC}}^{2} \times R_{\mathrm{dc} \_ \text {control }}
$$

where $I_{\mathrm{DC}}$ is the DC bias current for the variable inductor.

\section{2) Transformer Loss}

For the magnetic control, it is much easier to analyze the transformer loss due to the constant frequency operation. However, for the traditional frequency controlled LLC resonant converter, the operating switching frequency is variable, which brings difficulty to the transformer power loss analysis. In addition, the transformer optimization is much easier for the magnetically controlled LLC resonant converter. Please note that the traditional power loss analysis method for the transformer is used here.

\section{3) Control Circuit Loss}

The control circuit loss is mainly generated by the voltage controlled current source (VCCO), and the control circuit loss can be calculated based on the following equation.

$$
P_{\text {control }}=V_{\text {supply }} \times I_{\mathrm{DC}}
$$

where $V_{\text {supply }}$ is the voltage of the $\mathrm{VCCO}$, and $I_{\mathrm{DC}}$ is the DC bias current of the variable inductor.

\section{Design Methodology}

Unlike the traditional frequency control, the design of the switching frequency operation range is the main focus, while for the magnetic control, the design of the variable resonant inductor is crucial. The system specifications are summarized in Table II.

Step 1 Calculation of the transformer turns ratio $n$

Firstly, the transformer turns ratio $n$ is determined based on the input voltage and output voltage requirement.

$$
n=\frac{210}{2 \times 48} \approx 2.2
$$

In the prototype, transformer turns radio $n=2.3$ is made. Therefore, $n=2.3$ is used for the following calculations.

Step 2 Selection of the resonant capacitor $C_{\mathrm{r}}$

The design considerations for the resonant capacitor $C_{\mathrm{r}}$ are: 1 ) voltage rating; 2) commercial available capacitance value. The voltage stress for the resonant capacitor can be expressed as

$$
C_{\mathrm{r}, \min }=\frac{V_{\mathrm{o}}^{2}}{R_{L, \text { min }} f_{s}\left(2 V_{C r \text {,rating }}-V_{\mathrm{in}, \text { min }}\right) V_{\mathrm{in}, \text { min }}}
$$

TABLE II

System Specifications

\begin{tabular}{rcc}
\hline \hline Parameter & Designator & Value \\
\hline Input voltage & $V_{\mathrm{in}, \min } \sim V_{\mathrm{in}, \max }$ & $190 \sim 210 \mathrm{~V}$ \\
Output voltage & $V_{\mathrm{o}}$ & $48 \mathrm{~V}$ \\
Output power & $P_{\mathrm{o}, \min } \sim P_{\mathrm{o}, \max }$ & $50 \sim 200 \mathrm{~W}$ \\
Switching frequency & $f_{\mathrm{s}}$ & $100 \mathrm{kHz}$ \\
\hline \hline
\end{tabular}

The voltage stress is set as $400 \mathrm{~V}$, then, the minimum resonant capacitor $C_{\mathrm{r}, \mathrm{min}}$ equals $17.26 \mathrm{nF}$ is calculated. Based on the commercial available capacitor values, finally, $C_{\mathrm{r}}=27$ $\mathrm{nF}$ is selected.

Step 3 Selection of the magnetizing inductor $L_{\mathrm{m}}$

There are two considerations when designing the magnetizing inductor: 1) maximum voltage gain requirement; 2) resonant network root-mean-square (RMS) current, which is related to the conduction loss.

The maximum voltage gain $G_{\max }$ can be determined according to the input voltage, output voltage, and transformer turns ratio.

$$
G_{\text {max }}=\frac{V_{o} \times n}{V_{\text {in,min }} / 2}=\frac{48 \times 2.3}{190 / 2} \approx 1.16
$$

In order to satisfy the voltage gain requirement during the whole operation range, the converter should achieve the maximum gain under the worst case, that is, when input voltage reaches its minimum value, and the output power reaches its maximum value. From (8), the maximum voltage gain of the magnetically controlled LLC resonant converter can be expressed as

$$
M_{\max }=\frac{1}{\sqrt{\frac{(b c-a d)^{2}}{a^{2}+c^{2}}}}
$$

Based on (21), the relationship between the maximum voltage gain $M_{\max }$ and the magnetizing inductor value $L_{\mathrm{m}}$ can be obtained as shown in Fig. 9. It can be seen that with the increase of the magnetizing inductor value, the corresponding maximum voltage is decreased. Therefore, in order to satisfy the system voltage gain requirement, the magnetizing inductor value should be less than $132 \mu \mathrm{H}$.

In order to guarantee ZVS operation for the primary switches $\mathrm{S}_{1}$ and $S_{2}$, their currents $i_{\mathrm{S}_{1}}$ and $i_{\mathrm{S}_{2}}$ should be negative before their driving signals come, so their body diodes can be turned on. Clearly, the worst case to achieve ZVS operation for the converter is when the input voltage reaches its maximum value. The charge stored in the drain-to-source capacitance of switch $S_{1}, C_{\mathrm{ds} 1}$ should be extracted completely during the dead time. Since the dead time is relatively small compared with the switching period, the resonant inductor current during the dead time can be assumed to be constant at $i_{L_{\mathrm{r}} \text { dead }}$, which can be approximately expressed by the magnetizing inductor peak 


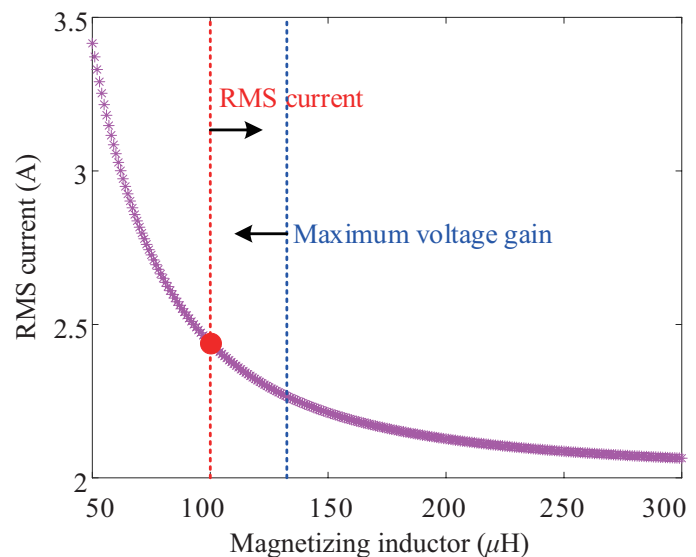

Fig. 10. Relationship between the RMS resonant network current and the magnetizing inductor value.

current as shown in (22).

$$
i_{L L_{-} \text {dead }}=i_{L \mathrm{~m}_{-} \mathrm{pk}}=\frac{n V_{o} D}{2 L_{\mathrm{m}} f_{\mathrm{s}}}
$$

where $D$ is the duty cycle of the switch, and it equals 0.5 .

Therefore, the following inequality should be satisfied to achieve ZVS operation for the primary switch $S_{1}$.

$$
Q=i_{\text {Lr_dead }} \times t_{\text {dead }} \geqslant 2 C_{\text {ds } 1} V_{\text {in,max }}
$$

Then, the expression for the magnetizing inductor $L_{\mathrm{m}}$ can be derived as

$$
L_{\mathrm{m}} \leqslant \frac{n V_{\mathrm{o}} D t_{\text {dead }}}{4 C_{\mathrm{ds} 1} V_{\mathrm{in}, \max } f_{\mathrm{s}}}
$$

In this research, $t_{\text {dead }}=100 \mathrm{~ns}$, and $C_{\mathrm{ds}}=22 \mathrm{pF}$ are selected. Then, a boundary value for the magnetizing inductor $L_{\mathrm{m}}$ equal to $3000 \mu \mathrm{H}$ can be calculated.

Fig. 10 shows the relationship between theresonant network RMS current and the magnetizing inductor value. Clearly, a higher magnetizing inductor value will result in a lower RMS resonant network current, and when the magnetizing inductor value is greater than $100 \mu \mathrm{H}$, the RMS current decreasing slope is reduced. So the magnetizing inductor value greater than 100 $\mu \mathrm{H}$ is required.

Finally, based on Figs. 9 and 10, the magnetizing inductor value $L_{\mathrm{m}}=120 \mu \mathrm{H}$ is selected.

Step 4 Design of the variable resonant inductor $L_{\mathrm{r}}$

As previously mentioned, the maximum value of the variable resonant inductor is determined based on the ZCS operation of the secondary rectifier. So the maximum variable resonant inductor value is calculated based on the following equation.

$$
L_{\mathrm{r}, \max }=\frac{1}{4 \pi^{2} C_{\mathrm{r}} f_{\mathrm{s}}^{2}}=93.8 \mu \mathrm{H}
$$

To satisfy the ZVS operation (9), the minimum variable

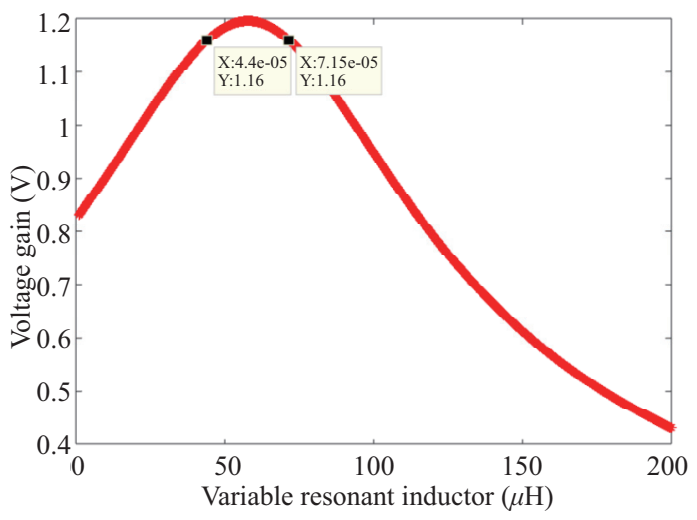

Fig. 11. Voltage gain curve when $f_{\mathrm{s}}=100 \mathrm{kHz}, C_{\mathrm{r}}=27 \mathrm{nF}$, and $L_{\mathrm{m}}=120 \mu \mathrm{H}$.

resonant inductor value should be greater than $57.8 \mu \mathrm{H}$. According to the voltage gain expression, there are two values that can satisfy the voltage gain requirement $\left(G_{\max }=1.16\right)$ as shown in Fig. 11, one equals $71.5 \mu \mathrm{H}$, another one equals $44 \mu \mathrm{H}$. In order to achieve the ZVS operation, the minimum variable resonant inductor value is selected as $71.5 \mu \mathrm{H}$.

Next, thedesign considerations for the variable resonant inductor is discussed.

In this research, EE42 core framework with PC47 core material [29] are selected to implement the variable inductor. The airgap for the core is $0.6 \mathrm{~mm}$. Then, the inductance factor $A_{L}$ can be calculated according to the following equation.

$$
A_{L}=\frac{\mu_{0} A_{\mathrm{e}}}{g}
$$

where $\mu_{0}$ is permeability of free space and $A_{\mathrm{e}}$ is the effective area of the core.

Then, inductance factor $A_{L}=266 \mathrm{nH}$ can be calculated. The turns ratio is obtained when the variable inductance reaches its maximum value.

$$
N_{\mathrm{AC}}=\sqrt{\frac{L_{\mathrm{r}, \max }}{A_{L}}}
$$

Based on (27), $N_{\mathrm{AC}}=19$ is calculated. According to the simulation model in [20], Fig. 12(a) shows the simulation results of the DC bias current and the variable inductance for different control winding turns $N_{\mathrm{DC}}$. From the simulation results shown in Fig. 12(a), it can be seen that a higher control winding turns require a small range of DC bias current. For the control winding loss, based on (18), the equivalent dc resistance $R_{\mathrm{dc} \_ \text {control }}$ can be calculated.

$$
R_{\text {dc_control }}=\frac{2 \rho L_{\text {avg }} N_{\mathrm{DC}}}{S}
$$

Then, the control winding loss can be expressed as

$$
P_{\text {control_LB }}=I_{\mathrm{DC}}^{2} R_{\mathrm{dc} \_ \text {control }}
$$




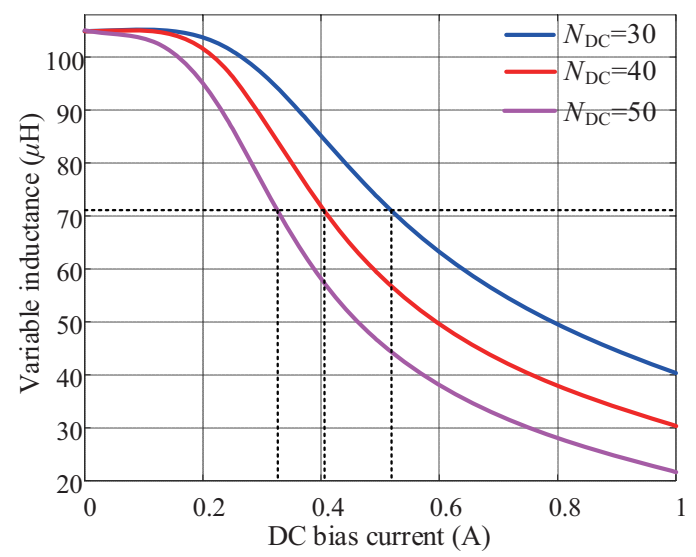

(a)

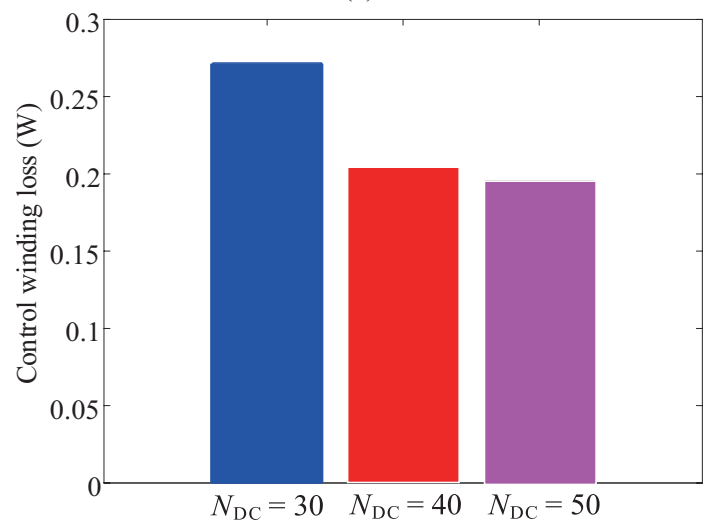

(b)

Fig. 12. Comparison between different control winding turns. (a) Variable inductance value versus the DC bias current for different control winding turns $N_{\text {DC }}$ (b) Control winding loss comparison.

where $I_{\mathrm{DC}}$ is the DC control current for the variable inductor.

Clearly, different control windings will only influence the control winding loss. Based on the simulation model, the comparison between different control winding turns in terms of control winding loss is shown in Fig. 12(b). Please note that since the control winding only takes a small space, the same wire is used to implement the control winding. The DC control current range is determined by the simulation results to satisfy the variable inductance range in this paper. Based on Fig. 12 (b), it can be seen that when $N_{\mathrm{DC}}=50$, the corresponding control winding loss is the smallest. When the control winding turns is small $\left(N_{\mathrm{DC}}=30\right)$, the required DC control current is large, which increases the control winding loss; when the control winding turns is increased $\left(N_{\mathrm{DC}}=40\right)$, the required $\mathrm{DC}$ control current is reduced, so the control winding loss is decreased; however, when the control winding turns is further increased $\left(N_{\mathrm{DC}}=50\right)$, although the required DC control current is reduced, the reduction is not obvious when compared with the control current reduction from $N_{\mathrm{DC}}=30$ to $N_{\mathrm{DC}}=40$, which makes the control winding loss reduction not obvious, and it also increases the complexity to implement a variable inductor with large control winding turns. Therefore, based on the above analysis, control winding turns $N_{\mathrm{DC}}=40$ is selected. The design flow chart for the LLC resonant converter with magnetic control is shown in Fig. 13.

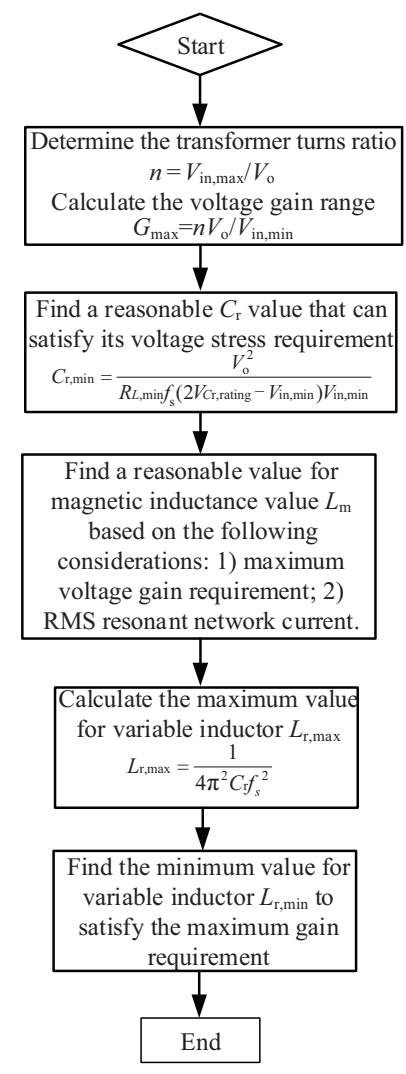

Fig. 13. Flow chart of the proposed design methodology for the LLC resonant converter with magnetic control.

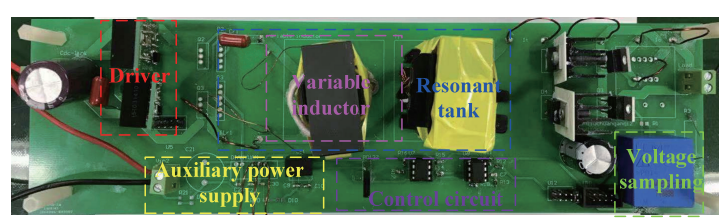

(a)

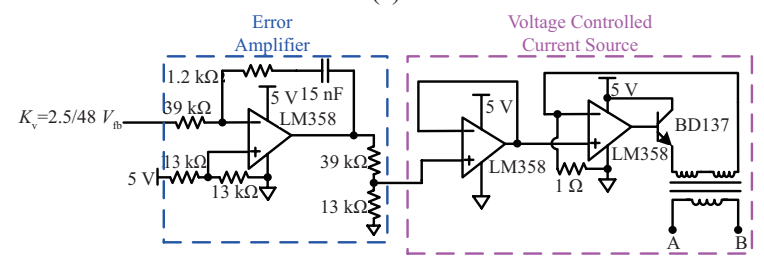

(b)

Fig. 14. Experimental prototype. (a) Experimental setup. (b) Control circuit.

\section{EXPERIMENTAL RESULTS}

In this part, an experimental prototype has been built to verify the theoretical analysis. The experimental setup is shown in Fig. 14(a), and the implemented control circuit to achieve the closed loop control is illustrated in Fig 14(b), where LM358 is adopted to form a PI controller, and combined with NPN transistor BD137, a voltage controlled current source is built to provide DC bias current for the variable inductor. The circuit parameters and component part numbers are shown in Table III. In practice, the leakage inductance of the transformer 
TABLE III

Circuit Parameters and Component Part Numbers

\begin{tabular}{ccc}
\hline \hline Unit & Component & Parameter \\
\hline & Resonant capacitor $C_{\mathrm{r}}$ & $27 \mathrm{nF}$ \\
& & $71.5 \sim 93.8 \mu \mathrm{H}$ \\
& Resonant inductor $L_{\mathrm{r}}$ & $N_{\mathrm{DC}}=42 \mathrm{PC} 47$ \\
& $g=0.6 \mathrm{~mm}$ \\
& & $130 \mu \mathrm{H}$ \\
Half-bridge & Magnetizing inductor $L_{\mathrm{m}}$ & $150 \mu \mathrm{F}$ \\
LLC resonant & Output capacitor $C_{\mathrm{o}}$ & $2.3: 1$ \\
converter with & Turns ratio $N$ & KSA 1 \\
control & Switch $\mathrm{S}_{1}, \mathrm{~S}_{2}$ & IPA60R170CFD7X \\
& Diode $\mathrm{D}_{1}, \mathrm{D}_{2}, \mathrm{D}_{3}, \mathrm{D}_{4}$ & IDP15E0XKSA1 \\
& Power source & Agilent 6813B \\
& DC electronic load & Chroma 63205A \\
\hline \hline
\end{tabular}
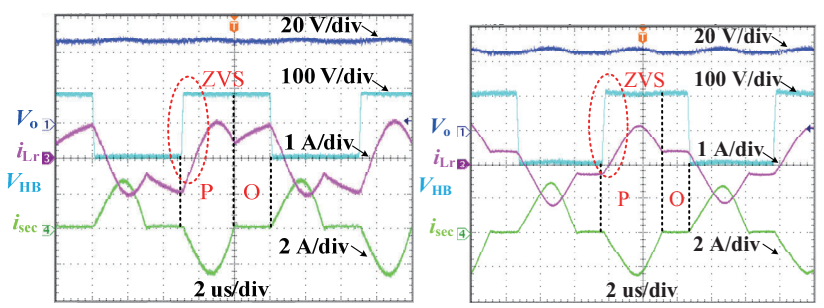

(a)
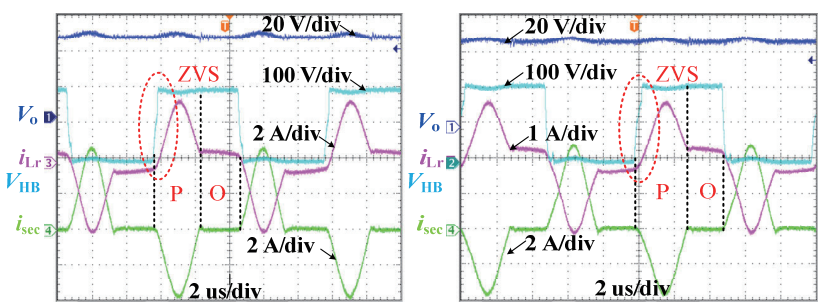

(b)
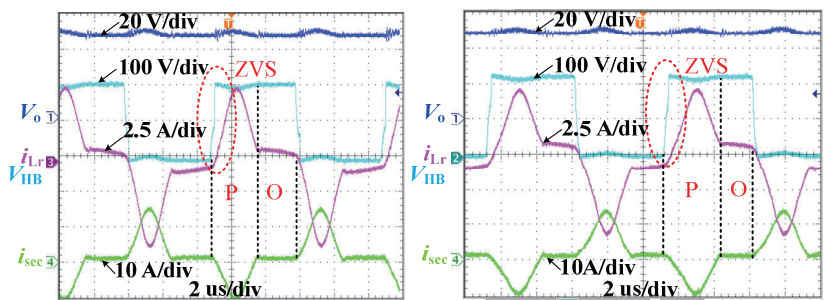

(c)

Fig. 15. Experimental waveforms when input voltage equals $190 \mathrm{~V}$ and $210 \mathrm{~V}$. (a) $P_{\mathrm{o}}=50 \mathrm{~W}$. (b) $P_{\mathrm{o}}=150 \mathrm{~W}$. (c) $P_{\mathrm{o}}=200 \mathrm{~W}$.

can be utilized as part of the variable inductor, so the design requirements for the transformer are reduced.

Fig. 15(a) shows the experimental waveforms of the resonant network input voltage $V_{\mathrm{HB}}$, the resonant inductor current $i_{\mathrm{L} r}$, the secondary side current $i_{\text {sec }}$ and the output voltage $V_{\mathrm{o}}$ when $P_{\mathrm{o}}=50 \mathrm{~W}$, the input voltage equals $190 \mathrm{~V}$ and $210 \mathrm{~V}$, respectively. From the resonant inductor current waveforms, it can be seen that the resonant inductor value is adjusted to keep the output voltage constant with different input voltage. In addition, the resonant inductor current $i_{L_{\mathrm{r}}}$ lags behind the resonant voltage $V_{\mathrm{HB}}$, which ensures the inductive operation of
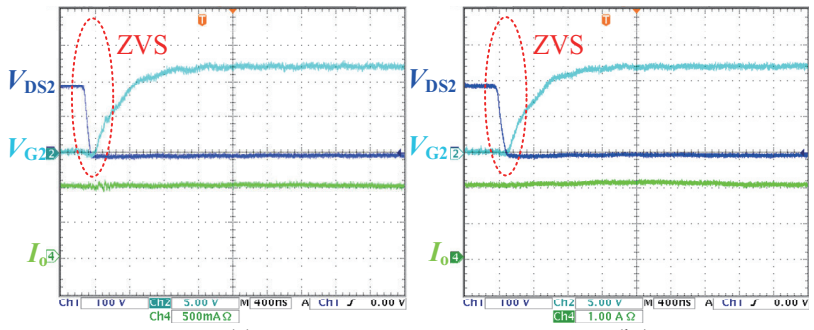

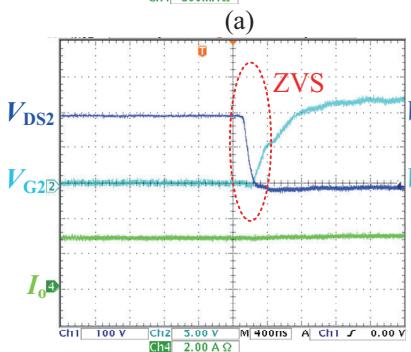

(c)

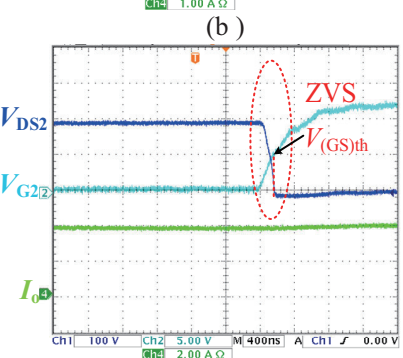

(d)
Fig. 16. Experimental waveforms of the drive signal $V_{\mathrm{G} 2}$ and drain-to-source voltage $V_{\mathrm{DS} 2}$ of switch $\mathrm{S}_{2}$ and output current $I_{\mathrm{o}}$. (a) $P_{\mathrm{o}}=50 \mathrm{~W}$. (b) $P_{\mathrm{o}}=100 \mathrm{~W}$. (c) $P_{\mathrm{o}}=150 \mathrm{~W}$. (d) $P_{\mathrm{o}}=200 \mathrm{~W}$.

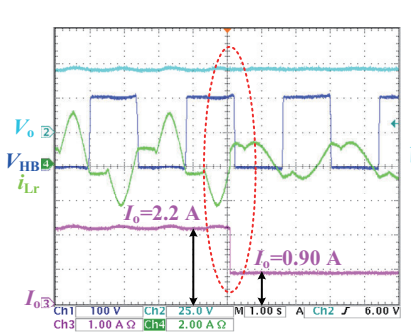

(a)

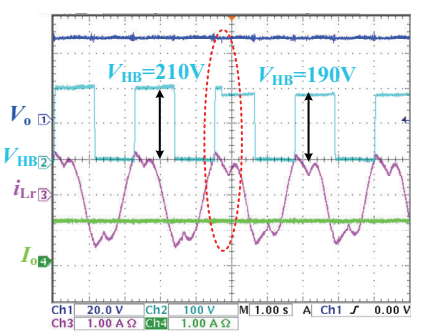

(b)
Fig. 17. Dynamic response of the proposed converter. (a) Load changes from 105 to $43 \mathrm{~W}$. (b) Input voltage changes from 210 to $190 \mathrm{~V}$.

the resonant network input impedance. So the ZVS operation for the primary switches is achieved. In addition, the secondary side current $i_{\text {sec }}$ decreases to zero before the corresponding turn-off signal for the rectifier is coming, so there is no reverse recovery problem for the secondary rectifier and the ZCS operation is achieved.

Similarly, Fig. 15(b) and (c) show the experimental waveforms when the output power equals $150 \mathrm{~W}$ and $200 \mathrm{~W}$, respectively. It can be seen that the ZVS operation for the primary switches and ZCS operation for the secondary rectifier still hold.

Fig. 16 shows experimental waveforms of the drive signal $V_{\mathrm{G} 2}$ and the drain to source voltage $V_{\mathrm{DS} 2}$ of switch $\mathrm{S}_{2}$ and the output current $I_{\mathrm{o}}$ with different output power levels. It can be seen that before the switch is fully turned ON (after the gate threshold voltage $V_{(\mathrm{GS}) \mathrm{th}}$ ), the voltage across the switch decreases to zero, thus the ZVS operation is achieved.

Fig. 17(a) shows the dynamic response of the converter when the load changes from $105 \mathrm{~W}$ to $43 \mathrm{~W}$. It can be seen that when the output power changes, the variable inductor changes accordingly to keep the output voltage constant. Fig. 17(b) shows the dynamic response when the input voltage is reduced 


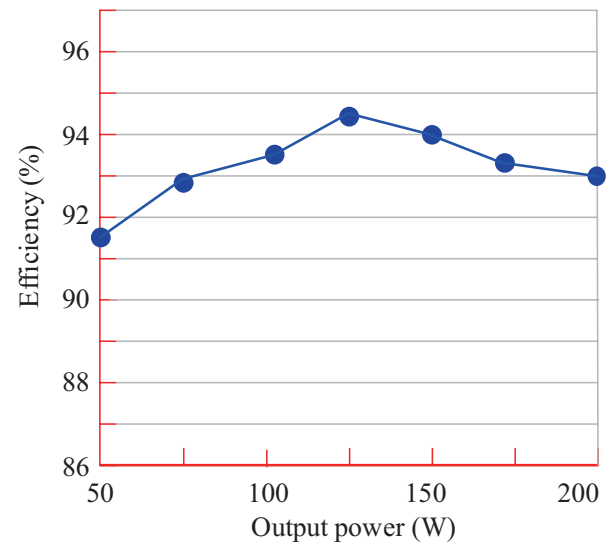

Fig. 18. Converter efficiency with different output power.

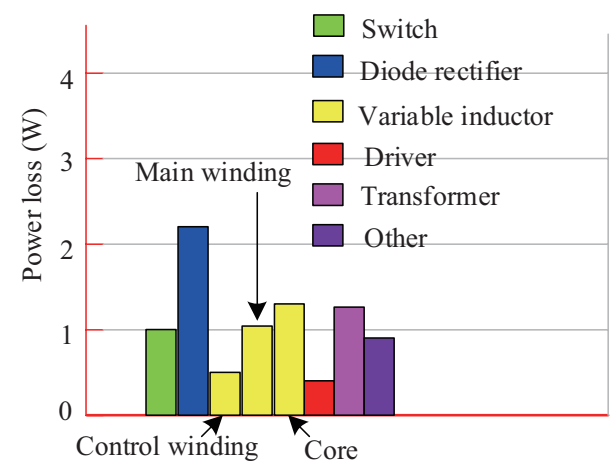

Fig. 19. Power loss analysis when $P_{\mathrm{o}}=120 \mathrm{~W}$.

from 210 to $190 \mathrm{~V}$. It can be seen that the response time is short and the dynamic characteristic is good. This is mainly because the variable resonant inductance value can be adjusted right after the change is happened.

Fig. 18 shows the system efficiency curve with different output power. The measured maximum efficiency is $94 \%$ when the output power equals $120 \mathrm{~W}$. In addition, the estimated power loss analysis for the converter when $P_{\mathrm{o}}=120 \mathrm{~W}$ is given in Fig. 19. It can be seen that since ZVS operation is achieved for the primary switches, only the conduction losses are included, but a high $R_{\mathrm{DS}(\text { on })}$ resistance $\left(R_{\mathrm{DS}(\mathrm{on})}=0.29 \Omega\right)$ for the switches will lead to a relatively high conduction loss. In addition, although the rectifier diodes operate with ZCS, their conduction losses cannot be neglected due to the relatively high RMS current that flows through the diodes and their high forward voltage $\left(V_{\mathrm{F}}=0.95 \mathrm{~V}\right)$. In the future work, low forward voltage diodes, synchronous rectifier technology, and halfbridge rectifier can be adopted to further improve the system efficiency. For the variable inductor, both the control winding loss and core loss are included.

\section{CONCLUSION}

Traditional LLC resonant converter adopts frequency control or phase shift control to regulate the output voltage, which suffers from a wide switching frequency operation range, poor EMI performance, and complicated magnetic component and driver circuit design. The magnetically controlled LLC resonant converter proposed in this paper can solve the abovementioned problems. In this paper, the LLC resonant converter with magnetic control is analyzed, which including the system control strategy, operation analysis, voltage gain, and soft switching operation. Then, based on the analysis, a design methodology for the magnetically controlled LLC resonant converter is proposed. By adopting the proposed methodology, the ZVS operation and ZCS operation for the primary switches and secondary rectifier can be achieved, respectively. Finally, the experimental results are presented to validate the theoretical analysis. The main focus and contribution of this paper lies in the following two aspects: 1) a comprehensive analysis for the LLC resonant converter with magnetic control is presented; 2) a design methodology is proposed for the LLC resonant converter with magnetic control.

\section{REFERENCES}

[1] T. Qian and C. Qian, "An adaptive frequency optimization scheme for LLC converter with adjustable energy transferring time," in IEEE Transactions on Power Electronics, vol. 34, no. 3, pp. 2018-2024, Mar. 2019.

[2] L.-C. Shih, Y.-H. Liu, and Y.-F. Luo, "Adaptive dc-link voltage control of llc resonant converter," in CPSS Transactions on Power Electronics and Applications, vol. 3, no. 3, pp. 187-196, Sep. 2018.

[3] H. Wu, C. Wan, K. Sun and Y. Xing, "A high step-down multiple output converter with wide input voltage range based on quasi twostage architecture and dual-output LLC resonant converter," in IEEE Transactions on Power Electron., vol. 30, no. 4, pp. 1793-1796, Apr. 2015.

[4] Y.-K. Tran, F. D. Freijedo, and D. Dujic, "Openloop power sharing characteristic of a three-portresonant LLC converter," in CPSS Transactions on Power Electronics and Applications, vol. 4, no. 2, pp. 171-179, Jun. 2019.

[5] Demirel I, Erkmen B, "A very low-profile dual output LLC resonant converter for LCD/LED TV applications," in IEEE Transactions on Power Electronics, vol. 29, no. 7, pp. 3514-3524, Aug. 2014.

[6] Y. Wei, Q. Luo, S. Chen, P. Sun and N. Altin, "Comparison among different analysis methodologies for LLC resonant converter," in IET Power Electronics, vol. 12, no. 9, pp. 2236-2244, Aug. 2019.

[7] Y. Wei, Q. Luo, X. Du, N. Altin, J. M. Alonso and A. Mantooth, "Analysis and design of the LLC resonant converter with variable inductor control based on time domain analysis," in IEEE Transactions on Industrial Electronics. (Early access)

[8] H. Gui, Z. Zhang, X. He and Y. Liu, "A high voltage-gain LLC microconverter with high efficiency in wide input range for PV applications," in IEEE Applied Power Electronics Conference and Exposition (APEC), Fort Worth, TX, pp. 637-642, 2014.

[9] D. Kim, S. Moon, C. Yeon and G. Moon, "High-efficiency LLC resonant converter with high voltage gain using an auxiliary LC resonant circuit," in IEEE Transactions on Power Electronics, vol. 31, no. 10, pp. 69016909, Oct. 2016.

[10] Z. Li, T. Wu, G. Zhang and R. Yang, "Hybrid modulation method combining variable frequency and double phase-shift for a $10 \mathrm{~kW} \mathrm{LLC}$ resonant converter," in IET Power Electronics, vol. 11, no. 13, pp. 21612169, Nov. 2018.

[11] X. Yudi, M. Xingkui, Z. Zhe and Y. Shi, "New hybrid control for wide input full-bridge LLC resonant DC/DC converter,"2018 3rd International Conference on Intelligent Green Building and Smart Grid (IGBSG), pp. 1-4, 2018.

[12] Y. Wei, Q. Luo, X. Lv, P. Sun, and X. Du, "Analysis and design of function decoupling high voltage gain DC/DC converter," in Journal of Power Electronics, vol. 19, no. 2, pp. 380-393, Mar. 2019.

[13] H. Wu, T. Mu, X. Gao and Y. Xing, "A secondary-side phase-shift-controlled LLC resonant converter with reduced conduction loss at normal operation for hold-up time compensation application," in IEEE Transactions on Power Electronics, vol. 30, no. 10, pp. 5352-5357, Oct. 2015. 
[14] Z. Hu, Y. Qiu, Y. Liu and P. C. Sen, “A control strategy and design method for interleaved LLC converters operating at variable switching frequency," in IEEE Transactions on Power Electronics, vol. 29, no. 8, pp. 4426-4437, Aug. 2014.

[15] X. Sun, X. Li, Y. Shen, B. Wang and X. Guo, "A dual-bridge LLC resonant converter with fixed-frequency PWM control for wide input applications," in IEEE Transactions on Power Electronics, vol. 32, no. 1, pp. 69-80, Jan. 2017.

[16] H. Hu, X. Fang, F. Chen, Z. J. Shen and I. Batarseh, "A modified highefficiency LLC converter with two transformers for wide input-voltage range application," in IEEE Transactions on Power Electronics, vol. 28, no. 4, pp. 1946-1960, Jun. 2013.

[17] H. Vu and W. Choi, "A Novel dual full-bridge LLC resonant converter for $\mathrm{CC}$ and $\mathrm{CV}$ charges of batteries for electric vehicles," in IEEE Transactions on Power Electronics, vol. 65, no. 3, pp. 2212-2225, Mar. 2018.

[18] Y. Wei, Q. Luo, X. Du, N. Altin, A. Nasiri and J. M. Alonso, "A Dual Half-Bridge LLC Resonant Converter With Magnetic Control for Battery Charger Application," in IEEE Transactions on Power Electronics, vol. 35, no. 2, pp. 2196-2207, Feb. 2020.

[19] Y. Chen and Y.-F. Liu, "Latest advances of LLC converters in high current, fast dynamic response, and wide voltage range applications," in CPSS Transactions on Power Electronics and Applications, vol. 2, no. 1, pp.59-67, Mar. 2017.

[20] J. M. Alonso, M. S. Perdigão, D. G. Vaquero, A. J. Calleja and E. S. Saraiva, "analysis, design, and experimentation on constant-frequency DC-DC resonant converters with magnetic control," in IEEE Transactions on Power Electronics, vol. 27, no. 3, pp. 1369-1382, Mar. 2012.

[21] Y. Wei, Q. Luo, S. Chen, Q. He and L. Zhou, "A High Efficiency Single Stage Bi-directional Battery Charger with Magnetic Control," 2018 IEEE International Power Electronics and Application Conference and Exposition (PEAC), Shenzhen, pp. 1-6, 2018.

[22] J M, Alonso M, Perdigao G. Z, Abdelmessih et al., "SPICE modelling of variable inductors and its application to single inductor LED driver design," in IEEE Transactions on Power Electronics, vol. 64, no. 7, pp. 5894-5903, Dec. 2016.

[23] J M, Alonso G, Martínez M, Perdigão et al., "A systematic approach to modelling complex magnetic devices using SPICE: application to variable inductors," in IEEE Transactions on Power Electronics, vol. 31, no. 11, pp. 7735-7746, May. 2016.

[24] Y. Wei, N. Altin, Q. Luo and A. Nasiri, "A high efficiency, decoupled on-board battery charger with magnetic control,"2018 7th International Conference on Renewable Energy Research and Applications (ICRERA), Paris, pp. 920-925, 2018.

[25] V. S. Costa, M. S. Perdigão, A. S. Mendes and J. M. Alonso, "Evaluation of a variable-inductor-controlled LLC resonant converter for battery charging applications,"IECON 2016 - 42nd Annual Conference of the IEEE Industrial Electronics Society, Florence, pp. 5633-5638, 2016.

[26] G. Martínez, J. M. Alonso and R. Osorio, "Analysis and design of a unidirectional resonant switched-capacitor step-up converter for OLED lamp driving based on variable inductor," in IEEE Journal of Emerging Electric Power Systems, vol. 6, no. 3, pp. 1106-1115, Sep. 2018.

[27] Y. Wei, Q. Luo, Z. Wang, L. Wang, J. Wang, and J. Chen, "Design of LLC resonant converter with magnetic control for LEV application,"2019 IEEE 10th International Symposium on Power Electronics for Distributed Generation Systems (PEDG), Xi'an, pp. 854-859, 2019.

[28] C. Yang, T. Liang, K. Chen, J. Li and J. Lee, "Loss analysis of halfbridge LLC resonant converter,"2013 1st International Future Energy Electronics Conference (IFEEC), Tainan, pp. 155-160, 2013.

[29] [Online]. Available: https://product.tdk.com/info/zh/catalog/datasheets/ ferrite_mz_sw_e_zh.pdf.

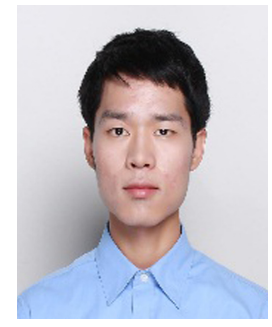

Yuqi Wei was born in Henan, China, in 1995. He received his B.S. degree in Electrical Engineering from Yanshan University, Hebei, China, in 2016, and his M.S. degree in Electrical Engineering from University of Wisconsin-Milwaukee (UWM), Wisconsin, U.S.A., in 2018. He received another M.S. degree in Electrical Engineering from Chongqing University, Chongqing, China, in 2019. From August, 2019, he is working toward his Ph.D. degree in University of Arkansas, Arkansas, U.S.A. His current research interests include topology, modelling and control of power converters, applications for battery charger converter

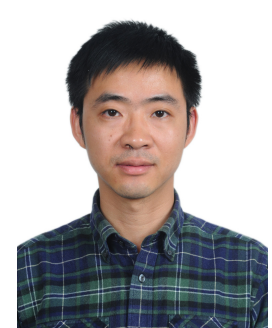

Quanming Luo was born in Chongqing, China, in 1976. He received his B.S., M.S., and Ph.D. in Electrical Engineering from Chongqing University, in 1999, 2002, and 2008, respectively. He was with the Emerson Network Power Co. Ltd., Shenzhen, China, as a Research and Development Engineer from 2002 to 2005. Since 2005, he has been with the College of Electrical Engineering, Chongqing University, where he is currently a Professor. He is the author or coauthor of more than 40 papers in journal or conference proceedings. His current research interests include LED driving systems, communication power systems, power harmonic suppression, and power conversion systems in electrical vehicles.

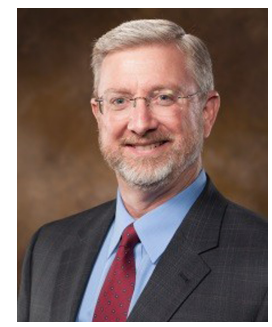

Alan Mantooth received the B.S. and M.S. degrees in Electrical Engineering from the University of Arkansas, Fayetteville, AR, USA, in 1985 and 1986, respectively, and the Ph.D. degree from the Georgia Institute of Technology, Atlanta, GA, USA, in 1990. He then joined Analogy, a startup company in Oregon, where he focused on semiconductor device modelling and the research and development of modelling tools and techniques. In 1998, he joined the faculty of the Department of Electrical Engineering at the University of Arkansas, where he currently holds the rank of Distinguished Professor. His research interests now include analog and mixed-signal IC design \& CAD, semiconductor device modelling, power electronics, and power electronic packaging. Dr. Mantooth helped establish the National Center for Reliable Electric Power Transmission (NCREPT) at the UA in 2005. He serves as the Executive Director for NCREPT as well as two of its centers of excellence: the NSF Industry/University Cooperative Research Center on GRid-connected Advanced Power Electronic Systems (GRAPES) and the Cybersecurity Center on Secure Evolvable Energy Delivery Systems funded by the U.S. Department of Energy. Dr. Mantooth holds the 21st Century Research Leadership Chair in Engineering. He serves as the Immediate Past-President for the IEEE Power Electronics Society in 2019-2020. Dr. Mantooth is a Fellow of IEEE, a member of Tau Beta Pi and Eta Kappa Nu, and Registered Professional Engineer in Arkansas. 